\title{
A IRREDUTIBILIDADE METODOLÓGICA ENTRE NEUROLOGIA E PSICANÁLISE
}

Fernando Belo

Universidade de Lisboa

1. Não falarei aqui explicitamente de Fenomenologia, mas a análise proposta, extracto simplificado da primeira parte do capítulo 6 (sobre a psicanálise) do meu livro Le Jeu des Sciences avec Heidegger et Derrida, 2007, L'Harmattan, pertence a uma tentativa de reformulação do discurso fenomenológico que tem em conta, além de Husserl, os seus dissidentes nomeados no título, bem como a dimensão filosófica das principais ciências europeias do século XX, recuperada pelo levantamento da sua suspensão kantiana.

\section{A questão}

2. Queria ocupar-me aqui do 'fenómeno' do cérebro, como dizer? mais do que 'objecto' da ciência, do que ele objecta à ciência que se ocupa dele. Há duas ciências, por assim dizer: uma região da biologia chamada neurologia e entre as chamadas psicologias, a única que conheço um pouco, a psicanálise. Para tratar desta questão não é preciso ser neurologista, psicanalista nem psiquiatra. Creio que é necessário e suficiente ser-se capaz de precisar os domínios ou áreas de que se ocupam quer a Neurologia quer a Psicanálise, quais são os respectivos laboratórios e métodos. Tentar responder brevemente a estas duas questões permitirá entender porque é que há, tão manifestamente, irredutibilidade entre as duas disciplinas.

3. Comecemos pela Neurologia. Sendo uma especialidade adentro da Biologia, tem antes de mais que ter em conta o conjunto do domínio desta, que é o que lhe prescreve as funções do sistema neuronal e quero crer que aí começam os problemas de delimitação da área da Neurologia, dada a importância que justamente nela têm a priori, nas razões mesmas pelas quais se escolhe trabalhar nela, as questões de psicologia humana. Resumirei o argu- 
mento. Como se sabe, todas as células dum organismo têm o mesmo programa genético, mas uma boa parte dele está recoberto em cada célula especializada, só activas a parte que tem a ver com a síntese das moléculas específicas da própria célula. $\mathrm{O}$ que já basta para perceber que o alcance da actividade desses genes se limita à membrana da célula, o nível de funções superiores relevando dos diferentes órgãos e seus tecidos especializados. No que diz respeito a um mamífero, esses órgãos conhecem dois sistemas mais um: o sistema que alimenta o metabolismo de todas as células e que fornece ao sangue nutrientes e oxigénio, por um lado, e por outro o sistema que, além do esqueleto que sustenta o conjunto, permite buscar esse alimento e fugir de ser alimento de carnívoros, isto é, órgãos de percepção, cérebro e nervos, músculos da mobilidade. Estes dois sistemas asseguram a reprodução do organismo, o 'mais um', o da sexualidade, releva da reprodução da espécie.

4. Primeira conclusão a tirar em relação à Neurologia: sendo o sistema neuronal humano fruto da evolução dos vertebrados, ele é constituído na sua estrutura essencial para essas duas funções, de caça e fuga a ser caçado, que são próprias da animalidade, as funções de inteligência, consciência e deliberação, que tanto prezamos, são primariamente a entender como as necessárias às estratégias para essas duas funções. Enquanto que as características humanas da linguagem duplamente articulada e dos usos sociais, que variam com as tradições dos povos e são aprendidas por cada indivíduo que nasce, relevam de outra linhagem evolutiva, como mostrou Vygostky, e vêm enxertar-se na estrutura, em seus três sistemas, herdada da evolução biológica. Ora bem, este motivo de duas linhagens, uma relevando da alimentação biológica e a outra da habitação 'social, rege em princípio a partilha entre as duas disciplinas.

\section{A neurologia, ciência do cérebro que não do discurso nem do sonho}

5. Venhamos então à Neurologia: a primeira questão a pôr, me parece, a mim que sou leigo, é a da função dos neurónios enquanto células especializadas, diferentes das duas centenas de outras células dos tecidos dos vertebrados. O que os diferencia claramente das outras células é o facto de constituírem uma rede entre si, cada um se ligando a outros por uns milhares de sinapsis: essa rede faz com que sejam afectados uns pelos outros, e também pelo exterior a partir dos órgãos de percepção, graças aos nervos tipo óptico, acústico, etc. É nesta rede que o animal sabe de si e do seu envolvimento - 'saber', 'scire' em latim, 'con' sigo -, os neurónios são as células da consciência. Sujeitos à acção química, de tipo hormonal, dos neurotransmissores, dando passagem, ou impedindo-os, a influxos de electricidade iónica (que lhe permite jogar com a química).

6. A comunicação entre dois falantes, no esquema corrente, dá-se a dois níveis fenomenológicos, este cerebral ou neuronal, jogando em electricidade 
e química, e o da voz, jogando por ondas acústicas do ar. O problema está em ser a voz, para os outros, a maneira de ter acesso ao neuronal, ser a sua 'ex-pressão' (pressão do ar vinda para fora), com um risco duplo, o de engano e o de dissimulação 'expressa'. O grande progresso da Neurologia, desde a descoberta dos neurónios nos finais do século XIX, adveio das invenções de instrumentos, de ordem química e eléctrica sobretudo, dando acesso cada vez mais detalhado à rede neuronal. E aqui supõe o leigo que está a dificuldade insuperável dos neurologistas: com excepção das lesões ou amputações, como conciliar o que analisam dos neurónios com o que estes 'sabem' de si e do envolvimento, como testar a correlação de tal zona neuronal com 'comportamentos'. O problema também se encontra noutras especialidades da Medicina, quando o médico tem que perguntar: 'onde lhe dói?' Quando o neurologista recorre ao discurso do sujeito para esclarecer as observações feitas com a sua aparelhagem (excepto ablação e lesões, com os respectivos efeitos), qual é a fiabilidade do discurso, que pode obviamente enganar-se sobre si, simplificar-se, enganar o neurologista conscientemente ou não, etc.

7. A leitura do livro de M. Jouvet de 1992, Le sommeil et le rêve, Odile Jacob, traduzido em português, é muito elucidativa, já que esclarece bastante do sono e nada do sonho, como o próprio autor conclui num desabafo no final duma vida de investigação. Enquanto que a sua geração de especialistas compreendeu bem as duas fases alternativas do sono, uma hora e meia de sono de ondas cerebrais lentas e uma vintena de minutos de sono paradoxal, com ondas agitadas, sem ter necessidade da colaboração activa dos que dormiam, a tentativa de estabelecer uma correlação 'científica' entre as ondas cerebrais agitadas e o sonho, implicava acordar a pessoa e aceitar o seu testemunho 'subjectivo' de que estava ou não a sonhar. Jouvet di-lo claramente: "o sonho constitui um fenómeno subjectivo cuja realidade só pode ser apreendida pela recordação que se guarda dele após ter acordado; ora, o sonho aparece ao mesmo tempo que um conjunto de actividades fisiológicas específicas que se designam habitualmente pelo termo de "sono paradoxal"" (p. 80, subl. meu). Ora bem: que conteúdo dar ao termo 'subjectivo'? À confissão de que ele não pode ser apreendido pela instrumentação neurológica, que capta os fenómenos químicos e eléctricos neuronais, e ao facto de não ser localizada no organismo, como as dores, podemos acrescentar que a recordação acordada é dada nas ondas acústicas do ar, na voz, e que o relato dele é inevitavelmente afectado, não só por esse carácter de 'recordado', como pelo seu desfasamento em relação ao tempo do sonho. Noutro passo (p. 68), recomenda que se tome nota dessa recordação o mais rapidamente possível após o acordar, para impedir a deformação dessa recordação. Voltaremos a esta questão a propósito da psicanálise.

8. Ainda que seja muito provável que os fenómenos fisiológicos neuronais sejam 'onticamente' o mesmo que os fenómenos ditos 'psíquicos', isto é que o sono paradoxal seja um sonho, já que é próprio dos neurónios a auto 
afectação, e ainda que os animais também sonhem, como experiências com a ablação em gatos do locus caruleus -, a conclusão a tirar é que os sonhos, ao contrário do sono, não fazem parte do domínio da Neurologia, já que não são susceptíveis de serem captados metodologicamente pelo seu arsenal próprio. Basta ler o capítulo sobre os sonhos que Jouvet registou e o que sabe dizer deles, para se perceber que, não só é duma magreza confrangedora comparado com a interpretação psicanalítica, como não há nada de 'neurológico' nessa interpretação. O que não é de admirar, se fizermos uma comparação: sendo o pensamento e a fala fenómenos de índole cerebral tanto quanto o sonho, alguma vez algum neurologista pensou que poderia analisar as línguas humanas, as suas regras sintácticas ou fonéticas, com os seus métodos científicos? Ao ver-se as ondas dum electroencefalograma de alguém calado, pode-se saber em que língua é que ele está a pensar?

\section{Uma semiótica experimental do discurso neurótico na sua relação à sexualidade}

9. O campo fica livre, assim espero que aceitem, para tentar caracterizar a cientificidade da psicanálise, a metodologia da sua análise, através da sua abordagem dos sonhos, que o livro de 1900, Traumdeutung, inaugurava de forma exemplar. Se permitirem a um profano caracterizar as ciências médicas, à diferença das biologias, como a) um saber teórico e experimental de tipo biológico, químico e físico, b) que se exerce numa relação terapêutica, isto é dual, de singular a singular, c) a pedido do paciente que se queixa de certos sintomas, d) essa relação devendo durar todo o tempo do tratamento até à cura, até que os sintomas desapareçam, é fácil ao tal profano concluir que apenas no ponto a) a psicanálise se distingue das outras especialidades, ou seja no ponto das metodologias, de cuja irredutibilidade estamos a tratar. Se compararmos as pretensões do médico Freud, no Esboço duma psicologia cientifica de 1895, com a Interpretação dos sonhos de cinco anos mais tarde, parece óbvio o abandono das preocupações de tipo neurológico (próprias da época, claro, Ramon y Cajal descobrira os neurónios, 5 anos antes) - de busca de localização anatómica cerebral ou de fisiologia dos neurónios - das instâncias de que se vai ocupar: esse abandono manifesta que ele teve em conta esta irredutibilidade metodológica como condição da instalação do paradigma psicanalítico. É claro que há um outro ponto de discussão, mas desse o profano não sabe dizer: há curas, os sintomas desaparecem? Quem pode sobre isso ter uma palavra segura? A dos pacientes não será suficiente, porque testemunha só do seu caso, a dos não praticantes enferma de ser exterior ao paradigma: em bom rigor kuhniano, apenas os próprios praticantes terão conhecimento suficiente, teórico e prático, para de tal poderem discutir entre si.

10. Mas esse abandono da orientação de tipo neurológico não implica uma ruptura total com o saber de tipo biológico, em que as questões energé- 
ticas têm lugar primordial. A grande descoberta de Freud - que creio continuar a ser, um século mais tarde, a razão de ser da prática psicanalítica, e só dela - foi, citando Ricœur, "o acesso à energética apenas pela via da interpretação", ou ainda "o carácter híbrido da psicanálise", foi a da relação intrínseca do discurso dos humanos com a sexualidade. É justamente o que, se há curas, permite colocar o estatuto da psicanálise entre as ciências médicas: o duma semiótica experimental do discurso neurótico em relação à energia sexual humana no seu laço à lei social. Semiótica paradoxal, em comparação com as dos contos populares ou doutras narrativas, ou com as semióticas poéticas: sendo uma ciência da linguagem, não se ocupa todavia das estruturas linguísticas, mas apenas dos sintomas neuróticos que justamente só se encontram no contexto da interpretação duma relação dual terapêutica, na explicitação 'da memória latente do paciente (dos seus sonhos manifestos, por exemplo) através da sua livre associação de ideias, em direcção aos pressupostos mais profundos do seu percurso histórico singular. Semiótica paradoxal ainda, porque fazendo-se, não sobre um discurso já dito ou escrito, como as outras, mas sobre o discurso 'enquanto se faz' na longa duração da terapia, mas também que muda pelo efeito dessa mesma terapia, que visa essa mudança, o desaparecimento dos sintomas e do sofrimento. Trata-se portanto duma semiótica experimental, a chamada experiência analítica, que em princípio a cura deve poder testar: "a libertação dum ser humano, escreveu Freud, dos seus sintomas neuróticos, inibições e anomalias caracteriais". ${ }^{2}$ Este carácter experimental é de tal maneira primordial que nada no discurso psicanalítico tem valor científico fora desta relação dual terapêutica, o que não deverá ter equivalente nas outras ciências médicas e seus métodos laboratoriais.

\section{As resistências como índice de 'real'}

11. Uma das objecções possíveis à cientificidade (à objectividade, como se diz) desta semiótica tem a ver com o facto de ela se exercer sobre as associações livres do paciente, portanto sobre a sua subjectividade mais acentuada. Com efeito, dizem-se aí muitos disparates, coisas incongruentes, sem sentido. Ora, em vez de se ofuscar, o terapeuta encoraja-o: "diga tudo o que lhe vier à cabeça, mesmo que lhe pareça idiota, chocante, indecente, sem relação com o que quer que seja; não me dissimule nada". Encoraja-o pois a evitar a vigilância da consciência (razão, ética, conveniências) nesse desfile de ideias libertadas. Se há assim suspensão dum certo aspecto do subjectivo do paciente, trata-se no entanto do que ele tem de 'social', de 'comum' com os outros: a associação de ideias será ainda mais 'subjectiva', singular. Mas

1 P. Ricœur, De l'interpétation, Essai sur Freud, Seuil, 1995², p. 366.

2 "L'analyse avec fin et l'analyse sans fin", 1937, cit. in F. Delbary, La Psychanalyse: une anthologie. 1. Les concepts fondamentaux, Pockett, 1996, p. 168). 
mais automática também, quase mecânica, como um rio fora das barragens, melhor entregue às leis hidráulicas do movimento dos fluidos que se possam jogar no próprio desfile. Cheio de figuras, deslizes, choques inesperados, eis no entanto que o terapeuta vê surgirem correlações que se repetem aqui e ali, que desenham contornos, configurações, nesse magma de ideias; e essas repetições revelam-se com frequência no bordo de certas paragens do discurso, de resistências a dizer que se manifestam por esquecimentos, lapsos ou outros actos falhados, intervenções súbitas da consciência vigilante que se autocensura, silêncios, desmentidos, risos, choros, negações, etc. Isto é, sintomas energéticos (diferenças de sentido e diferenças de força indissociavelmente) que estabelecem uma clivagem, uma margem, um limite que não se pode passar, uma fronteira fractural, digamos, entre o que se diz e o que não chega ao dizer. Além dessa fronteira encontram-se os nós discursivos escondidos que manifestavam os sintomas neuróticos que levaram a pedir a terapia. Esta, o fim da interpretação, consistirá neste lento avançar do jogo livre das associações em ordem a que esses nós cheguem à relação explícita possível com o discurso corrente do paciente. Dialógica e experimental, esta semiótica dum discurso no seu fazer-se deverá servir à interpretação do analista mas também à cura.

12. Ora, é nestas repetições e resistências diversas que a sexualidade se manifesta como sexualidade censurada, interdita, tingida muitas vezes de agressividade, sexualidade incestuosa e de ciúmes correlativos: isto é, ela manifesta-se como ligada à lei social. Censurada, não apenas em relação ao analista, mas antes de mais e sobretudo em relação à consciência vigilante do sujeito, que se ofusca com aquelas revelações e não quer crer nelas. Digamos que é justamente a 'subjectividade' livre do sujeito que é contrariada por esses sintomas falando e trabalhando nele a partir de alhures. Algo mexe e resiste, permanecendo 'autónomo' da consciência, algo de real; esse algo que se joga nele, ele não o reconhece como seu, como por vezes nos sucede com a experiência de estranheza de certos sonhos: como é que eu pude sonhar isto ? Que o paciente resista primeiro, seja surpreendido por esse íntimo de si muito estrangeiro a si, que ele se alivie no fim dos seus sintomas neuróticos, que as suas dores desapareçam por este trabalho-palavra dum real estranho vindo dele, que não se dá senão ao trabalho de interpretação do analista sem que o paciente saiba como é que aquilo chegou a um certo fim, eis o que torna plausível um estatuto de ciência médica à psicanálise, é certo que não como as outras.

13. Esta semiótica experimental dos discursos neuróticos nas suas relações à sexualidade ligada à lei social pode assim distinguir, como o seu inventor fará vinte anos mais tarde, três instâncias discursivas: a que se tece em redor do 'eu' que fala (Ego, com uma zona inconsciente à volta), a que deseja, pulsiona, além do que 'eu' crê querer e desejar (Id, a líbido recalcada) e a que resiste a estes desejos e pulsões, também além do que 'eu' quer (Super-ego, os interditos morais, o ideal, parcialmente também inconsciente). Sobre o lugar 
da sexualidade na psicanálise, um argumento de conveniência, exterior à psicanálise e acrescentando-lhe alguma verosimilhança, é o da sua invenção precoce pela evolução, se se põem em contraste as espécies mais evoluídas (aves e mamíferos) com as espécies assexuadas, como certos vermes ou a hidra da água doce (cissiparidade e outros processos), que não deixam cadáveres nem conhecem filiação, isto é indivíduos completamente distintos daqueles donde são originados. Com a sexualidade, excessiva e pulsional, a evolução inventou também progressivamente quer o par fêma / macho, quer o nascimento e a morte dos individuos, quer ainda a permanência em vida dos progenitores em simultaneidade com os seus rebentos, e portanto a possibilidade da lei, da aprendizagem. Não há que nos admirarmos que estes motivos apareçam centrais nas interpretações psicanalíticas.

\section{Pertinência e dissimulação}

14. E já agora, um segundo argumento de conveniência, também independente da psicanálise, mas que lhe esclarece um aspecto importante, o que se pode chamar o seu laboratório, que sem ele não há ciência. Recolhi-o dum texto muito lindo e curto de F. Flahault, discutindo a proposta duma lógica da conversa do filósofo americano P. Grice. ${ }^{3}$ Observa ele que em qualquer conversa, seja qual for o número de participantes, só há um fio da palavra, só um pode falar de cada vez como condição de que os outros escutem. Ora, esta estrutura implica que cada um, para tomar a palavra, seja socialmente obrigado a mostrar que tem o direito de o fazer, isto é, tem que provar a quem escuta que o que ele diz é pertinente para a conversa. Sem o quê, os outros rir-se-ão dele, tratá-lo-ão como estúpido ou como doido, não o escutarão. O que tem uma segunda implicação: não poderá dizer o que lhe vier espontaneamente à cabeça, tem que aprender a criticar-se previamente de si para si, tem que aprender a dissimular, a pensar duas vezes, a elaborar estratégias eventualmente, etc. Ora, como esta situação se apresenta a cada um desde miúdos de quem os adultos se riem, que corrigem, etc., isto implica que não é só a sexualidade, também a linguagem está desde o início ligada à lei, que nos impõe uma espécie de axioma pessoal de pertinência, para evitarmos de sermos considerados estúpidos, ou loucos. Lei que nos ensina a transgredi-la, pois que uma das suas regras é que não se pode mentir, mas só se pode ser pertinente dissimulando. E se é certo que a mentira é por este mecanismo que se forja, também o é a capacidade de se guardar segredo, seu ou de outrem, a de pensar, de fazer ficção, de vida interior, como se dizia no calão católico.

15. Porque é que isto é um argumento de conveniência da psicanálise? Porque justamente dá uma luz antropológica sobre a injunção psicanalítica acima 
referida: "diga tudo o que lhe vier à cabeça, mesmo que lhe pareça idiota, chocante, indecente, sem relação com o que quer que seja; não me dissimule nada". Não seja pertinente, não me esconda nada, quer dizer 'largue a sua dimensão social', venha para um laboratório, aqui deitado e relaxado, o mais perto possível da posição do sono e do sonho. O contraste é flagrante com a preocupação de M. Jouvet com o carácter 'subjectivo' do sonho enquanto recordação, com o evitar a deformação do seu relato após o acordar: essa preocupação é inexistente na psicanálise porque justamente essas deformações, impossíveis de evitar ou de controlar, fazem-se segundo a lógica estrutural que é a do sonho.

\section{Somos por vezes loucos durante a noite}

16. Todas as noites sonhamos várias.vezes, mas isso permanece um fenómeno tão extraordinário para qualquer neurologia ou psicologia ou filosofia que haverá que o considerar um pouco se se quer saber da cientificidade 'não normal' da psicanálise que pela interpretação deles começou. Acontece por vezes que, ao acordarmos, esfregamos os olhos dizendo: 'ah!, estou aqui, no meu quarto, estás aí, és a minha mulher, sou professor, moro nesta casa...'. Este alívio corresponde à recuperação de algumas marcas fundamentais da nossa identidade: estado civil, ofício e local de trabalho, morada, sei lá. Estas marcas perdem-se em certos sonhos, passados alhures, noutros tempos e sítios, com outras gentes, mas que não correspondem sem mais ao nosso passado, visto que há misturas, amálgamas, condensações e deslocamentos em linguagem técnica, repetições de cenas que nunca tiveram lugar (quando sonho que me falta ainda passar um exame do liceu). Há portanto regressão no tempo, para o passado, mas para um passado que nunca foi presente, que nunca aconteceu nem passou, que sucede em sonho pela primeira vez como se fosse muitas repetida. Sou sempre 'eu' no sonho, mas não sou exactamente 'eu' e muitas vezes no sonho não estranho essa diferença de identidade, não me espanto com as gentes desconhecidas, espantosas, que nele frequento lado a lado (e se me espanto, no sonho, é índice do que Freud chamou de "elaboração secundária", sem interesse nas associações de ideias).

17. Um outro aspecto de grande espanto no sonho, é que é ele e não eu que tem a iniciativa, que se me impõe, não sou senão um dos comparsas, por vezes reduzido ao papel de espectador, desenvolve-se segundo uma lógica de encenação ou figuração que me escapa, juntamente com as condensações e deslocamentos, uma lógica que não é a minha quando estou acordado. Esta 'iniciativa' manifesta-se também na força incisiva das cenas oníricas, ainda que gentes ou gestos sejam muitas vezes confusos, imagens fortes, sem nenhuma semelhança com o que, acordados, chamamos recordação ou imaginação. Se esta nitidez incisiva das imagens me acontecesse em estado de vigília, eu seria alucinado, louco: Moreau de Tours (1855) disse que "a loucura é o sonho do homem acordado", mas no sonho sou por vezes mais louco 
do que qualquer louco acordado. Ora, ele vem-me, esse sonho louco, quando me recolho em mim, deixo os outros e o mundo, os nossos usos e o nosso aqui e agora comum, quando deixo mesmo a minha intimidade consciente, os meus pensamentos e sentimentos, os meus projectos, as minhas vontades, a minha ética, os meus segredos. Estas estranhas gentes do 'meu' sonho são-me portanto mais íntimas a mim do que a minha intimidade mais próxima de mim, em que me reconheço como 'eu próprio', como diferente dos outros. Outros habitam em mim 'antes' de mim? Posso aliás dizer o 'meu' sonho? Ou sou eu pelo contrário que lhe pertenço? Mas como na noite de amanhã será um outro sonho ainda, de que pertença fugaz se trataria?

18. Esta é a grande questão que a psicanálise aborda, que ela procura compreender. Há que esperar que não seja susceptível de relevar do mesmo tipo de 'cientificidade' do que a da física de Newton, a neurologia de Jouvet ou a linguística de Gross. A questão a colocar é: fora de Freud, há alguma teoria consistente do sonho, seja 'científica', seja 'filosófica'? Alguma teoria consistente desta dupla lógica?

\section{Oscilação e identidade}

19. Há assim em nós duas lógicas muito diferentes, que Freud chamou "primária" e "secundária", uma tendo a primazia nos sonhos e nos casos mais patológicos das doenças mentais e a outra na nossa vida social adulta: uma lógica do sonho e uma lógica do estado de vigília, mas aquela assinala-se nos lapsos e outros fenómenos da psicopatologia da vida quotidiana, e ainda nas anedotas, assim como os sonhos são também trabalhados pela lógica vigilante, na tal elaboração secundária que procura atenuar os excessos da outra e evitar que o sonhador acorde. O que significa que não há oposição cortante entre as duas lógicas, mas uma oscilação. Tentemos um esboço de aproximação desta dupla lógica.

20. 'Eu sonhei que... P', diz 'eu' acordado, em que P é uma narrativa de várias sequências e personagens, entre as quais aquele que diz 'eu'. É uma narrativa mais ou menos confusa, bizarra, que 'eu' tem mais ou menos dificuldade em 'contar', em explicitar que 'quem' se tratava, 'aonde', e por aí fora. 'Eu' que conta sabe no entanto que foi aquele que diz 'sonhei que... P' quem sonhou: há portanto uma certa identidade entre 'eu (que estou) acordado', vigil (eu-vigil) e 'eu (que) sonhei' (eu-sonho). Mas entre eu-sonho e e eu-vigil há também uma tradução: da cena sonhada à cena contada, dum cenário imaginário a um cenário narrativo, das 'imagens' às 'palavas'. Esta tradução - na qual justamente o 'eu-vigil' hesita, resiste, gagueja - impede que a identificação entre 'eu-sonho' e 'eu-vigil' seja completa, total. Nem 'um só eu', nem 'dois 'eus', nem um 'nós', mas uma oscilação irredutivel, já que cada um dos 'eu'é e não é o outro. Com efeito, eu-vigil sabe que ele é 'eu-sonho', mas a minha experiência de sonhador [sic] parece permitir-me dizer que, quando se 
sonha, se sabe também no sonho que é o 'eu-vigil' que está a sonhar, apesar da loucura do sonho. Digamos que quando estou acordado, diante de outrem, eu sei (razoavelmente) quem vejo, o que ouço e o que digo, o que sinto, etc., sem nunca ser 'eu diante de mim': o que se chama con-sciência (scire, saber) é este co-saber de mim naquilo que, diante dos outros, sou. Ora, quando sonhamos, por muito bizarra que seja a cena sonhada, apesar da perda eventual da certas marcas da minha actualidade (ofício, residência, estado civil...), este co-saber não parece desaparecer totalmente: o alívio que se tem ao acordar dum pesadelo, quando se recuperam essas marcas perdidas, parece confirmá-lo. Ele seria o fio ligando eu-vigil a eu-sonho. Por outro lado, na interpretação do sonho no divã, o eu-vigil que o contoủ presta-se a séries de associações livres que permitem ao psicanalista ter acesso a uma certa lógica do sonho, num movimento inverso ao da tradução. Este fio entre ęu-vigil e eu-sonho não poderia ser percorrido em sentido inverso senão em relação com outrem, outra indicação de não identidade total entre os 'eu'.

21. Em que é que consiste a lógica da vigília ? Pode dizer-se, de forma aproximada, que se trata duma lógica textual, no sentido corrente (já que um sonho também é um texto): saber, por regras linguísticas e semióticas (rápidas demais para serem conscientes), compor um discurso - numa conversa, ou uma narrativa, sei lá - com um sentido coerente, predicável de um contexto relativo ao mundo, ilocucionado por um 'eu' a um 'tu', aqui e agora, implicando pertinência e capacidade de dissimulação. Trata-se duma lógica aprendida antropologicamente, no sistema familiar de usos em que se foi inserido ao nascer. O que implica também que essa lógica da vigília se articula nos comportamentos dos usos e costumes tribais que se aprenderam.

22. A lógica do sonho, por sua vez, supõe a desarticulação dos comportamentos (inibidos no sono paradoxal, ensinaram-nos os neurólogos), deixando no entanto que a visão e a audição guardem uma relação escondida à sexualidade, que os sonhos fariam ressoar e o acordar por sua vez inibiria. Nenhuma destas inibições sendo nunca completa - já que o fio nunca se quebra entre os dois estados, excepto talvez em casos extremos de loucura -, a oscilação entre as duas lógicas insere-se nas oscilações mais gerais que nós somos, entre dia e noite, entre atenção e relaxação. Ela é sem dúvida uma objecção forte a uma Fenomenologia de tipo husserliano.

\section{ABSTRACT}

In this paper, the author tries to show that Neurology and Psychoanalysis are irreducible to a common methodological pattern. Emphasizing the biological, chemical and physical basis of Neurology, the author puts forward the case of dream, as a phenomenon only attainable through the psychoanalytical approach. The psychoanalytical access to dream is discussed at length, and questions like the relationship between awake and dream I are considered. 